\title{
APPLICABILITY OF BUSINESS MODELS IN THE SOCIAL AND SOLIDARITY ECONOMY AMONG SOCIAL ENTERPRISES IN BULGARIA
}

\author{
K. Stoyanov*, G. Zhelyazkov \\ Department of Industry Business and Entrepreneurship, Faculty of Economics, Trakia University, \\ Stara Zagora, Bulgaria
}

\begin{abstract}
Social entrepreneurship in Bulgaria is known as a sector, but only a year ago it was legally recognized as a form of business activity. At the same time, the difference in the development of the sector in individual countries does not have a key influence on the implementation of the main activities and social goals of individual organizations. The existence of several business models, which are observed among enterprises in the social and solidarity economy sector, are in general not directly dependent on the regulatory environment in which they operate. This determines the ability to monitor the applicability of those business models in question under different external conditions. The article aims to look at how social enterprises in Bulgaria integrate the various business models, that are known in the sector and to what extent they are influenced by the existing legal framework in the country.
\end{abstract}

Key words: social entrepreneurship, solidarity economy, business model

JEL: L22, L31, O35

\section{INTRODUCTION}

Social enterprises have had a place in the economic life of most countries in the world for years. Starting from the position that behind their appearance there is a real need for positive social change, it makes their role and model of work differ depending on the circumstances that are specific to certain countries and regions. The existence of their generally applicable features, characteristics and operational properties allows us to study the sector as a whole.

According to the European Economic and Social Committee, which is one of the initiators of regular surveys on the social economy in Europe, published approximately every 4 years, the definition of the social economy should be common to the sector. Thus, the definition according to the EESC / CIRIEC (2012) is: a group of private enterprises with a formal structure,

\footnotetext{
*Correspondence to: Assist. Prof. Konstantin Stoyanov, PhD, Room 385, Faculty of Economics, Trakia University, Students Campus, 6000 Stara Zagora, Bulgaria, Tel: +35942699432, stoyanov.konstantin@gmail.com
}

independent in decision-making and with freedom of membership, created to meet the needs of its members through the market by producing goods and providing services, insurance and financing, and decision-making and the distribution of profits or surpluses among members are not directly linked to the members' capital or contributions, each of which has one vote, or is necessarily carried out in a democratic decision-making process with the participation of all. The social economy also includes private, formally established organizations, with decisionmaking independence and freedom of membership, which produce non-market services for households and whose surpluses, if any, cannot be a source of income for the economic operators who create, control or finance them.

According to the Law on Enterprises of the Social and Solidarity Economy, which is in force in Bulgaria since 02.05.2019, an extended definition of the social economy is introduced, which includes and expands its scope, together with that of the solidarity economy, as are the trends in the leading 
countries in the European Union. Thus, the Law stipulates that the Social and Solidarity Economy is a form of entrepreneurship aimed at one or more social activities and / or social goals carried out by enterprises, including through the production of various goods or services, in cooperation with state or local authorities or on their own. In addition, the sector is based on the following principles: the advantage of social over economic goals; association for public and / or collective benefit; publicity and transparency; independence from state authorities; participation of members, employees in management decisions.

\section{METHODS}

The study relies on desk research of enterprises of social and solidarity economy operating in Bulgaria and officially listed in the National register of social enterprises. A first overview of the sector will be drawn, including the legislative framework and requirements.

The three most suitable business models for the sector in Bulgaria will be drawn. Based on statistical data, social enterprises will be distributed to those different operating business models, according to their particularities.

\section{MAIN FINDINGS AND CONCLUSIONS}

The state of the social and solidarity economy sector in Bulgaria seems to have developed in recent years. Following the work of the Ministry of Labour and Social Works, including during the presidency of the European Council in 2018 and various organizations and media, which put the topic of the sector in public order, the entry into force of the Law on Enterprises of Social and Solidarity Economy in 2018 and its regulations from 2019 set a real legal and organizational framework for social enterprises in the country.

By default, any social enterprise is recognised under "Class A" status. Enterprises that can be qualified as "Class A+" must meet some of the following conditions, according to the Law on Enterprises of Social and Solidarity Economy:

- Its social added value is in municipalities that register unemployment above the national average;

- Over $50 \%$ or at least BGN 75,000 of the profit of the company is directed to social activities;

- At least 30 of the employees in the last 6 months are persons from vulnerable social groups.

As of the end of June 2020, there is only one enterprise in the National Register that falls into this category. "Class $\mathrm{A}+$ " enterprises are in fact those that can receive targeted incentives for their work, which will be remunerative and have a lasting effect on their activities. It is important to note that the National Register of Social Enterprises in Bulgaria actually considers applications from the beginning of 2020 , as the first registered one is from 24.01.2020. Therefore, as of 16.06.2020 there are actually registered and valid only 14 social enterprises on the territory of the country. Figure 1 shows the existing social enterprises and those that are in the process of verification, according to the National Register of Social Enterprises.

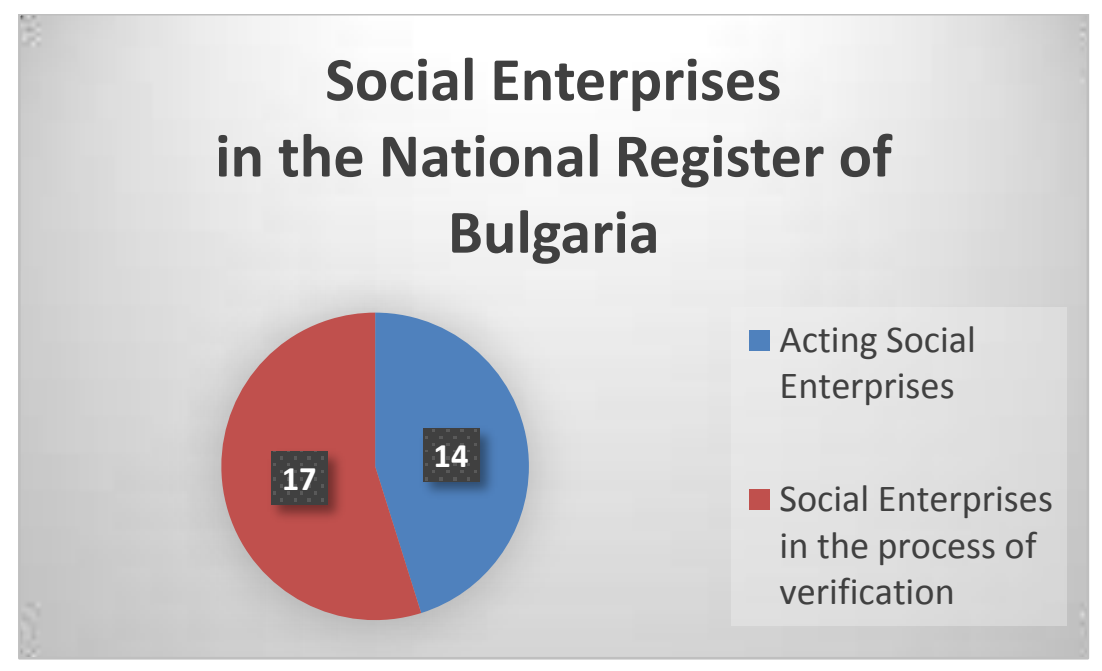

Figure 1. Social Enterprises in the National Register of Bulgaria Source: National Register of Social Enterprises 
It is important to clarify that these are not all operating social enterprises in Bulgaria. Previous studies, including one of one the authors of this article, show that their actual number is higher. Getting all economic entities in one register will take time and depends on the proactive actions of the legal owners of the companies. Nevertheless, those initial efforts are beneficial for the development of the sector, for its structuring, support and better research in the future.

However, the division into two types of social enterprises, according to the legal provisions, cannot provide reliable information on the actual functioning of the sector. Based on the studied types of business models in the social and solidarity economy and the current conditions for the development of the sector in Bulgaria, a division with three main groups, in which the different nuances and characteristics of the companies are delimited, seems most appropriate. This is due to the fact that the actual legislation in the field has been applied very recently - the last amendment to the law is from the end of February 2020 - and the results shall be analysed even further in time.

The structuring of the business models of social enterprises in Bulgaria is detailed in a previous study by the authors (Stoyanov \& Zhelyazkov, 2019). It examined the possible listings of business models of enterprises in the social economy, which are recognised in the literature and are differentiated by clear rules, reflecting their actual application in practice. Due to the lack of a unified approach in the sector internationally, the leading criterion in the selection is the possibility of applying these models in different national conditions, thus limiting the effects of national and local policies.

The grouping is based on the idea of Monzón \& Herrero (2016) to limit business models in the social economy to three. At the same time, this structuring is in line with the definition of one of the leading organizations in the world, which deals with the study of the social economy - EMES European Research Network - set in the study of Defourny \& Nyssens (2012).

These three models would be grouped as follows:
1. Economic and trade dimension, where leading for companies is their economic efficiency. In this respect, they are more like traditional businesses;

2. Social dimension, in which the leading is the social effect and maximum reaching the target groups defined by the companies.

3. Participatory dimension, in which the democratic decision-making process and independence of government is leading. The main goal is for external funding organizations not to influence the organizations, as well as for equality between members within them.

An analysis of the National Register of Social Enterprises as of June 2020 shows that representatives of all three types of business models, established as appropriate and adequate to the conditions in Bulgaria, can be found. However, the National Register has yet to work at full capacity, but even so far it has considered 100 applications, and 14 companies have already received the status of operating social enterprises. It is among them that an analysis of the applicability of business models has been made, depending on the main activity of the organizations and the way of engaging and integrating persons from vulnerable groups falling within the scope of their activities.

Thus, and based on the theoretical statement, which is adopted in terms of the existence of business models in the social economy in Bulgaria, they are divided into three main categories, which were discussed above:

1. Economic and trade dimension;

2. Social dimension;

3. Participatory dimension.

On the basis of the available information, which was provided during the registration of the social enterprises, main conclusions can be drawn regarding methods used to finance the main activity, to redistribute revenues and to manage the company. These characteristics are sufficient to identify each company with the corresponding business model of the above mentioned three types. This allows us to look at a sample of already registered social enterprises, which would lead to drawing some conclusions for the sector. Figure 2 examines the applicability of business models among the enterprises of the social and solidarity economy in Bulgaria. 


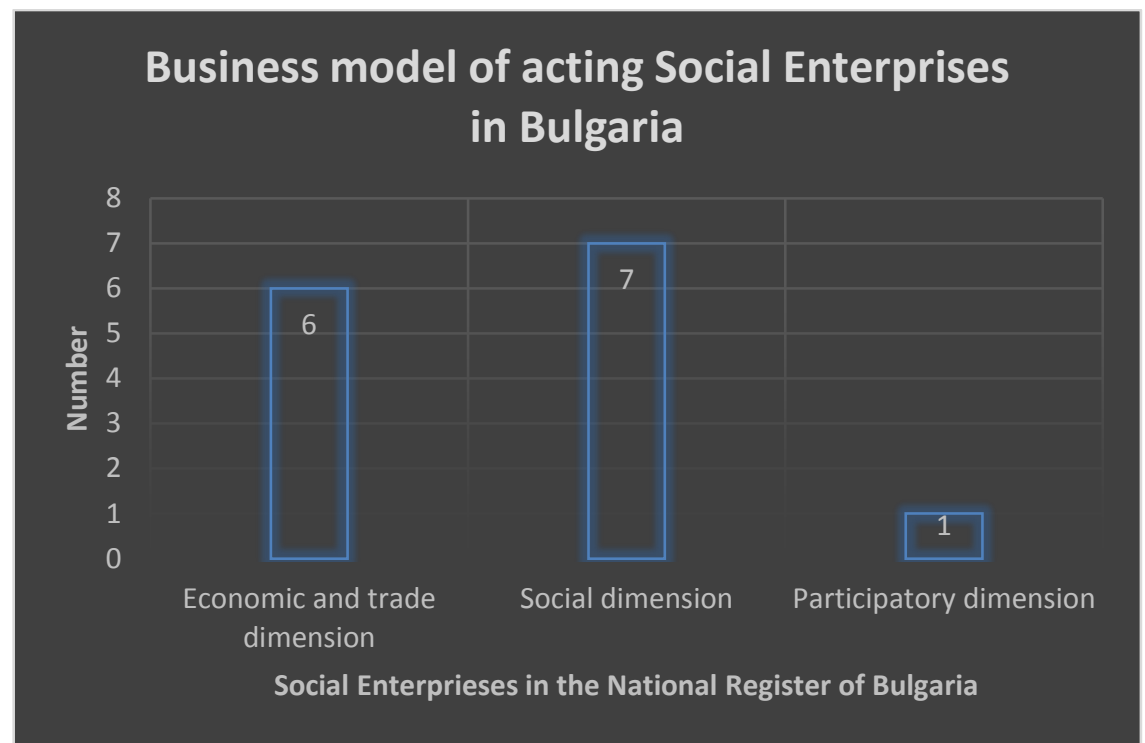

Figure 2. Distribution of business models among registered social enterprises in Bulgaria. Source: National Register of Social Enterprises

It is obvious that the first two groups of business models are predominant among social enterprises, which is rather logical, considering that the organizations that fall into the National Register are limited in terms of the number of staff and scope of activity. The last one, the third type of business model presupposes the presence of an important number of members, clearly distributed between the responsibilities and tasks of individuals or units and, accordingly, a different structure and organization of work. Even, the legislation assumes different categories for social enterprises depending on their origin. "Class $\mathrm{A}+$ " enterprises are most likely, by their nature, to fall within the characteristics of the third business model.

The existence of many different models in the social and solidarity economy is proof of the dynamic development of the sector and its ability to adapt to different conditions of the business environment. In short, any business model of enterprises in the social and solidarity economy must meet some of the following conditions: be driven by a socially significant goal, lead to positive change in the local community, be driven by entrepreneurial principles and use management strategies to successfully sell its goods or services.

However, somewhat logically, the most common business models of registered operating social enterprises in Bulgaria are those that rely on constant and secure income from economic activity close to the traditional enterprise; and those that try to integrate vulnerable people and representatives of the target groups with which they work on an everyday basis. In the conditions of initial regulation of the activity of the enterprises from the social and solidarity economy, it is rather expected that the main part of them will rely on their own revenues and sustainable models for generating income. The effects of structuring the sector and supporting it are likely to be explored in the coming years.

\section{REFERENCES}

1. EESC/CIRIEC, 2012, The Social Economy in the European Union, European Economic and Social Committee, Brussels

2. Law on Enterprises of Social and Solidarity Economy, in force since 02.05.2019

3. Stoyanov, K., Zhelyazkov, G., Business models in the social economy - review of successful practices, Trakia Journal of Sciences, Vol. 17, Suppl. 1, pp 176-180, 2019.

4. Monzón, J.L. \& Herrero, M., Identificación y análisis de las característicasidentitarias de la empresa social europea: aplicación a la realidad de los Centros Especiales de Empleode la economía española, CIRIECEspaña, Revista de Economía Pública, Social y Cooperativa, 87:295-326, 2016.

5. Defourny, J., Nyssens, M., The EMES approach of social enterprise in a comparative perspective, EMES European Research Network, 2012

6. National Register of Social Enterprises, https://secprod.mlsp.government.bg/index.p hp?section=REG, on 16.06.2020 